\title{
Usefulness of Addition of Orvus ES Paste and Sodium Lauryl Sulfate to Frozen Feline Semen
}

\author{
Tatsuji MIZUTANI ${ }^{1) *}$, Shiho SUMIGAMA ${ }^{2}$, Keiichi NAGAKUBO ${ }^{1)}$, Noriko SHIMIZU ${ }^{1)}$, Hiromichi OBA ${ }^{1)}$, \\ Tatsuya HORI ${ }^{1)}$ and Toshihiko TSUTSUI ${ }^{1)}$ \\ ${ }^{1)}$ Department of Reproduction, Nippon Veterinary and Life Science University, 1-7-1, Kyonan-cho, Musashino-shi, Tokyo 180-8602, \\ Japan and ${ }^{2)}$ Department of Anatomy, Physiology and Cell Biology, University of California, Davis, Davis 1916 CA, U.S.A.
}

(Received 14 September 2008/Accepted 26 August 2009/Published online in J-STAGE 5 November 2009)

ABSTRACT. It has been shown that addition of the surfactant Orvus ES paste (OEP) and its main component sodium lauryl sulfate (SLS) to boar or dog semen before freezing improves post-thaw sperm motility and protects acrosome caps. In this study, we investigated the usefulness of the addition of $\operatorname{OEP}(0,1,2$ and $4 \%)$ or $\operatorname{SLS}(0,1,2,3$ and $4 \mathrm{mg} / \mathrm{m} l)$ to cat ejaculates before freezing and their concentrations. Among the OEP addition groups, the 1\% OEP group showed higher sperm motility than the other groups. Among the SLS addition groups, the $3 \mathrm{mg} / \mathrm{m} l$ SLS group showed slightly higher sperm motility and viability than the other groups. Comparison between the $1 \%$ OEP and $3 \mathrm{mg} / \mathrm{m} l$ SLS addition groups suggested a higher percentage of sperm with an acrosome cap in the $1 \%$ OEP group. The other sperm properties did not significantly differ between the 2 groups. These results indicate that addition of $1 \%$ OEP or $3 \mathrm{mg} /$ $\mathrm{m} l$ SLS is effective for freezing of cat ejaculated semen.

KEY WORDS: acrosome cap, cat, frozen semen, orvus es paste, sodium lauryl sulfate.

J. Vet. Med. Sci. 72(1): 23-27, 2010

In regard to artificial insemination (AI) with frozen feline semen, intravaginal $[6,11,19]$ and intrauterine $[6,18,19]$ inseminations with ejaculates have each been reported in three studies, and intravaginal [20] and intrauterine [15, 20] inseminations with epididymal sperm have each been reported in one and two studies, respectively. In our 2003 year study using epididymal sperm [15], we added 7\% (v/v) glycerol and $1 \%$ Orvus ES paste (OEP, also known as Equex STM paste, Nova Chemical Sales, Inc., Scituate, MA, U.S.A.) to semen as cryoprotective agents and achieved a conception rate of $27.3 \%$. However, we did not evaluate the usefulness of addition of OEP for cryopreservation of feline semen or its optimal concentration. Addition of OEP along with glycerol for the cryopreservation of boar [12] and dog [16, 17] semen has been shown to protect the acrosome caps of sperm, thereby increasing and maintaining post-thaw sperm motility for a long period of time. In 2004, Axnér et al. [5] investigated the usefulness of Equex STM paste for cryopreservation of feline epididymal sperm and showed that addition $0.5 \%(\mathrm{v} / \mathrm{v})$ Equex STM paste led to greater protection of the acrosome caps of sperm after freeze-thawing than no addition, but sperm motility was lower (sperm survival was shorter) 4-6 hr after thawing than in the case of no addition. Our search of the literature revealed no studies in which addition of OEP for semen cryopreservation adversely affected post-thaw sperm motility. It remains unclear whether the results of the study by Axnér et al. [5] regarding cryopreservation of epididymal sperm apply to cryopreservation of cat ejaculates.

\footnotetext{
* Correspondence to: Mizutani, T., Department of Reproduction, Nippon Veterinary and Life Science University, 1-7-1, Kyonancho, Musashino-shi, Tokyo 180-8602, Japan.

e-mail : tatsuji@mizutani-ah.com
}

OEP is known to contain mainly sodium lauryl sulfate (SLS), but data on its concentration and the remaining constituents have not been published. It has been suggested that the effect of SLS might be exerted by modifying the structure of egg yolk lipoproteins in the extracellular medium [4]. Kato et al. [9] employed a freezing extender of boar semen containing SLS ( 1.2 to $1.6 \mathrm{mg} / \mathrm{m} l$ ) instead of OEP and reported that the percentages of normal acrosome caps and progressively motile sperm after thawing with addition of SLS were similar to those of OEP. Furthermore, several studies have reported the usefulness of frozen semen extender containing SLS in several animals (the cow [3], mouse [7], and goat [1, 2]). We have also reported previously that addition of $2 \mathrm{mg} / \mathrm{m} l$ of SLS to dog semen for freezing led to results similar to those obtained by addition of $0.75 \%$ OEP [8]. However, no studies have reported addition of SLS to cat semen for freezing.

In this study, we investigated the usefulness of addition of OEP or its main constituent SLS to cat ejaculates for freezing, determined their optimal concentrations and compared their usefulness as cryoprotective agents for freezing cat semen.

\section{MATERIALS AND METHODS}

Animals: Male cats bred and maintained in our colony were used in this experiment. Ten 3- to 12-year-old cats weighing $3.5-4.4 \mathrm{~kg}$ were used. These cats showed copulation capability and fertility. The animals were maintained in a room in which the temperature was adjusted to $23 \pm 2{ }^{\circ} \mathrm{C}$ and were individually kept in cages measuring $60 \times 90 \times$ $120 \mathrm{~cm}$. The animals were given commercial dry food (Hill's Feline Maintenance, Hill's-Colgate Ltd., Topeka, 
KS, U.S.A.) and water ad libitum. The female estrous cats maintained in our colony were appropriately used for semen collection.

This study was conducted in conformity with the animal study guidelines of Nippon Veterinary and Life Science University.

Semen collection: Semen was collected using an artificial vagina (AV) for cats that has previously been reported [14].

For semen collection, the penis of a male cat was advanced into the AV held between the forefinger and middle finger of the person collecting semen while the male cat was mounting an estrous cat and thrusting, and ejaculation was induced. Using the same AV, a second semen collection was performed. To avoid drying, $100 \mu l$ of egg yolk Tris-fructose citrate solution (EYT-FC) [18] was added to the semen immediately after collection.

Examination of semen quality: The semen volume was measured using a sample tube with $5 \mu l$ graduations. Sperm motility was assessed by the percentage of sperm actively moving forward using a test plate for semen quality examination (FA225, Fujihira Industry, Co., Ltd., Tokyo, Japan). The number of sperm, sperm viability and frequency of immature sperm were examined, as previously reported [10].

Frozen semen: The semen was centrifuged at $230 \times \mathrm{g}$ for 5 min to remove the seminal plasma, subjected to 1 st dilution with EYT-FC at $20^{\circ} \mathrm{C}$ to adjust the sperm count to $2 \times$ $10^{8} / \mathrm{ml}$ and then maintained in a water bath at $4^{\circ} \mathrm{C}$ for one $\mathrm{hr}$ for 1 st cooling. After 1st cooling, 2nd dilution of semen was performed using the secondary extender supplemented with $14 \%$ glycerol by dripping at $4{ }^{\circ} \mathrm{C}$; this took approximately 10 min with stirring using a stirrer. The semen was diluted with an equal volume of the extender, and thus, the final sperm concentration was $1 \times 10^{8} / \mathrm{ml}$, and the final glycerol concentration was 7\%. After the 2 nd dilution, the semen was put into $250 \mu l$ straws and equilibrated with glycerol for one hr. Then, the semen was frozen using a conventional freezer (Simple-type quick LNG freezer, Fujihira Industry, Co., Ltd., Tokyo, Japan). The temperature conditions for freezing were $-1.0^{\circ} \mathrm{C} / \mathrm{min}$ from $4^{\circ} \mathrm{C}$ to $-1.0^{\circ} \mathrm{C},-33.0^{\circ} \mathrm{C} / \mathrm{min}$ from $-1.0^{\circ} \mathrm{C}$ to $-50^{\circ} \mathrm{C}$ and $-58.4^{\circ} \mathrm{C} / \mathrm{min}$ from $-50^{\circ} \mathrm{C}$ to $-196^{\circ} \mathrm{C}$. When the temperature reached the maximal cooling temperature, $-196^{\circ} \mathrm{C}$, the semen was transferred to a liquid nitrogen container.

Semen preparations frozen for one week or more were thawed in a water bath at $37^{\circ} \mathrm{C}$ for $30 \mathrm{sec}$, and their qualities were examined. In the semen quality test, the motility and viability of sperm were evaluated, and the time-course changes in these were examined at $20^{\circ} \mathrm{C}$ after $1,2,4$ and 6 hr.

Experiment 1: Establishment of the concentration of OEP

The effect of OEP addition to EYT-FC was examined at final concentrations of $0,1,2$ and $4 \%(\mathrm{v} / \mathrm{v})$. To perform 4 types of experiment, it is necessary to use large numbers of sperm; therefore, a mixture of semen from 5 cats was used after 1st dilution and division into 4 equal parts if the quality of the individual semen samples was normal.
Freeze-thawed semen was evaluated for sperm motility, and the time-course changes in sperm motility were examined at $20^{\circ} \mathrm{C}$ after $1,2,4$ and $6 \mathrm{hr}$. This experiment was repeated six times.

Experiment 2: Establishment of the concentration of SLS

The effect of SLS addition to EYT-FC was examined at final concentrations of $0,1,2,3$ and $4 \mathrm{mg} / \mathrm{ml}$, and $1 \% \mathrm{OEP}$ was examined as the control. To perform 6 types of experiment, therefore, a mixture of semen from 6 cats was used after 1 st dilution and division into 6 equal parts if the quality of the individual semen samples was normal.

Freeze-thawed semen was evaluated for sperm motility and sperm viability at $20^{\circ} \mathrm{C} 1,2,4$ and $6 \mathrm{hr}$ after thawing. Sperm abnormality was also evaluated immediately after thawing. These experiments were repeated six times.

Experiment 3: Examination of the sperm acrosome cap

The presence or absence of acrosome caps in viable sperm was observed using the triple-stain technique (TST) [13] for OEP and SLS. Semen was collected from each of the 5 cats and was divided into 2 equal parts after 1st dilution. One part was diluted a second time with OEP at a final concentration of $1 \%$, while the other was diluted without adding OEP (for freezing). The TST was performed immediately after semen collection and after freeze-thawing, and the percentage of viable, acrosome-intact spermatozoa was determined. The same experiment was separately performed to examine the effect of $3 \mathrm{mg} / \mathrm{m} l \mathrm{SLS}$.

Statistical analyses: The significance of semen quality was analyzed among the groups by one-way ANOVA and Tukey-Kramer test. A p value of less than 0.05 was regarded as significant.

\section{RESULTS}

Experiment 1: Establishment of the concentration of OEP

The time-course changes in sperm motility after thawing are shown in Fig. 1. Sperm motility The sperm motility was $22.5 \pm 2.3 \%$ (mean $\pm \mathrm{SE}), 30.8 \pm 3.6 \%, 21.7 \pm 4.2 \%$ and 1.7 $\pm 1.8 \%$ in the $0,1,2$ and $4 \%$ OEP addition groups, respectively, immediately after thawing. While there was no significant difference among the 0,1 and $2 \%$ addition groups, sperm motility was clearly lower in the $4 \%$ addition group than in the other 3 groups $(\mathrm{P}<0.01)$. In regard to the timedependent changes, sperm motility was significantly higher in the $1 \%$ OEP addition group than in the 0 and $2 \%$ OEP addition groups until 1-2 hr post-thaw $(\mathrm{P}<0.01$ and $\mathrm{P}<0.05$, respectively) but was thereafter similar in the 1 and $0 \%$ OEP addition groups. Sperm motility rapidly decreased in the $2 \%$ OEP addition group, reaching $0 \%$ after $4 \mathrm{hr}$.

Experiment 2: Establishment of the concentration of SLS The time-course changes in sperm motility, sperm viability and sperm abnormality after thawing are shown in Figs. 2, 3 and 4, respectively. Sperm motility immediately after thawing was $20.0 \pm 6.8 \%, 22.5 \pm 5.6 \%, 24.2 \pm 4.1 \%, 35.0 \pm$ $2.0 \%, 33.3 \pm 2.3 \%$ and $40.8 \pm 4.1 \%$ in the $0,1,2,3$, and 4 $\mathrm{mg} / \mathrm{m} l \mathrm{SLS}$ and $1 \%$ OEP addition groups, respectively. It was clearly lower in the 0 and $1 \mathrm{mg} / \mathrm{m} l \mathrm{SLS}$ addition groups 


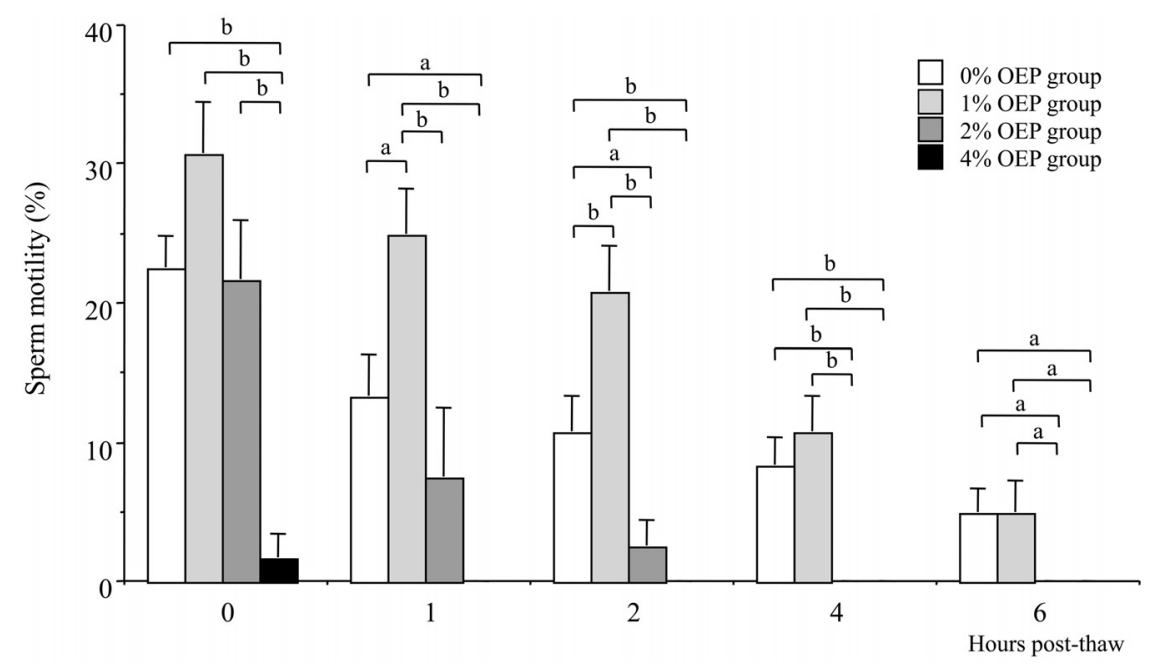

Fig. 1. Time-course changes in post-thaw feline sperm motility for each treated group. The error bars represent the standard error of the mean $(n=6)$. Significantly different between the two groups at $\mathrm{P}<0.05$ (a) and $\mathrm{P}<0.01$ (b).

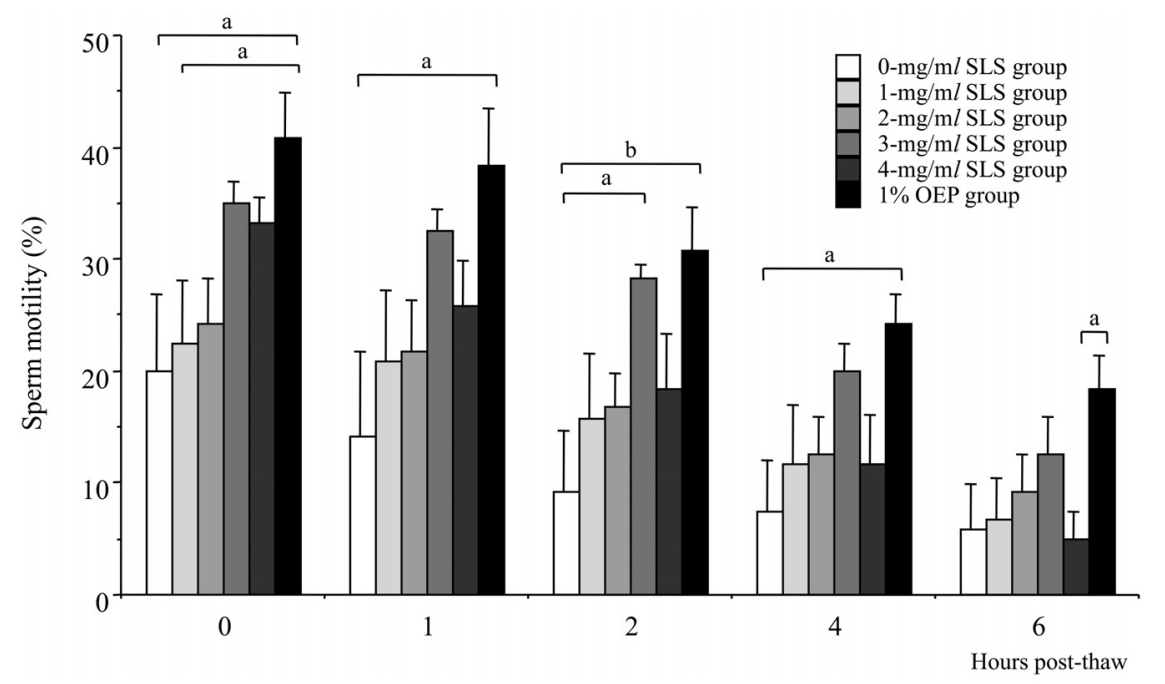

Fig. 2. Time-course changes in post-thaw feline sperm motility for each treated group. The error bars represent the standard error of the mean $(n=6)$. Significantly different between the two groups at $\mathrm{P}<0.05$ (a) and $\mathrm{P}<0.01$ (b).

than in the $1 \%$ OEP addition group $(\mathrm{P}<0.05)$ but was not significantly different among the 2,3 and $4 \mathrm{mg} / \mathrm{ml}$ SLS and $1 \% \mathrm{OEP}$ addition groups. Also, in regard to time-dependent changes, sperm motility clearly remained higher in the $1 \%$ OEP addition group than in the $0 \mathrm{mg} / \mathrm{m} l \mathrm{SLS}$ addition group until $4 \mathrm{hr}$ after thawing $(\mathrm{P}<0.01$ and $\mathrm{P}<0.05$, respectively). Sperm motility $2 \mathrm{hr}$ after thawing was clearly higher $(\mathrm{P}<0.05)$ in the $3 \mathrm{mg} / \mathrm{m} l \mathrm{SLS}$ addition group than in the 0 $\mathrm{mg} / \mathrm{m} l \mathrm{SLS}$ addition group. However, sperm motility showed no significant difference among the 1,2,3 and 4 $\mathrm{mg} / \mathrm{ml}$ SLS groups from immediately to $6 \mathrm{hr}$ after thawing. Sperm viability immediately after thawing did not significantly differ among the SLS addition and 1\% OEP addition groups. In regard to the time-dependent changes, sperm viability was clearly higher in the $1 \% \mathrm{OEP}$ addition group than in the $0 \mathrm{mg} / \mathrm{m} l \mathrm{SLS}$ group from 1 to $6 \mathrm{hr}$ after thawing $(\mathrm{P}<0.01$ and $\mathrm{P}<0.05$, respectively). $2 \mathrm{hr}$ after thawing, it was clearly higher $(\mathrm{P}<0.05)$ in the $3 \mathrm{mg} / \mathrm{ml}$ SLS group than in the $0 \mathrm{mg} / \mathrm{m} l \mathrm{SLS}$ group. However sperm viability did not differ significantly among the $1,2,3$ and $4 \mathrm{mg} / \mathrm{m} l$ SLS groups until $6 \mathrm{hr}$ after thawing. No significant difference was noted in the sperm abnormality rate immediately after thawing among the 6 groups.

Experiment 3: Examination of the sperm acrosome cap

The presence or absence of acrosome caps in viable sperm after freeze-thawing when $1 \%$ OEP or $3 \mathrm{mg} / \mathrm{ml}$ of 


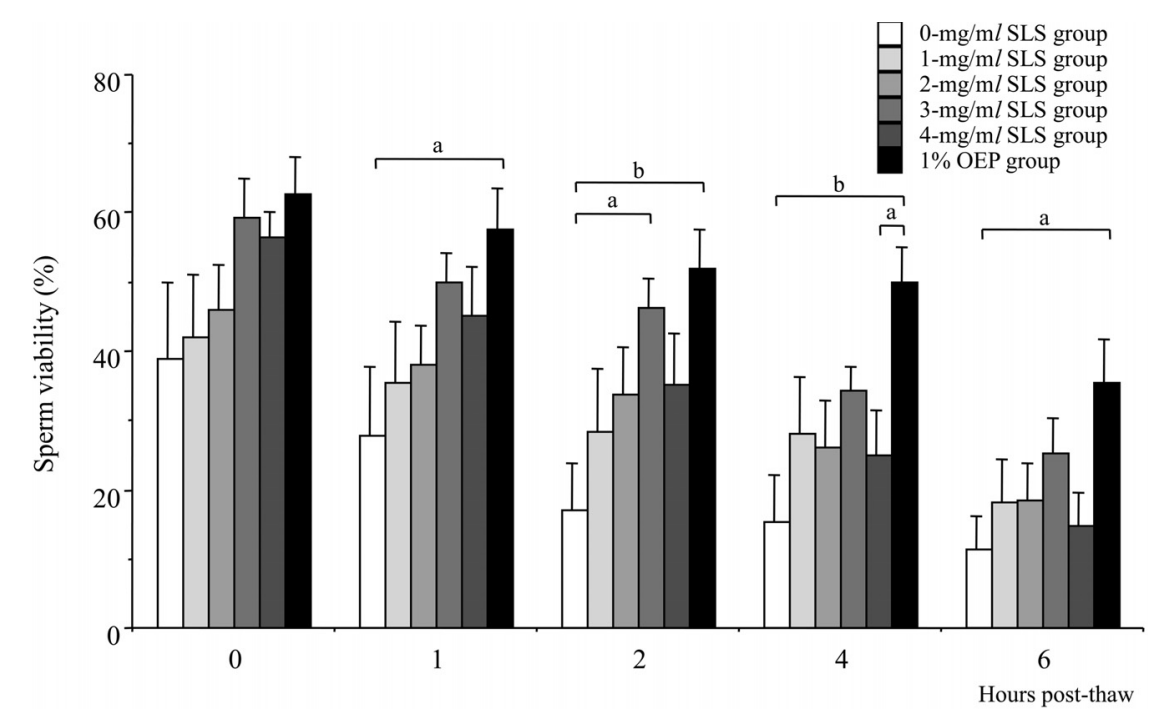

Fig. 3. Time-course changes in post-thaw feline sperm viability for each treated group. The error bars represent the standard error of the mean $(n=6)$. Significantly different between the two groups at $\mathrm{P}<0.05$ (a) and $\mathrm{P}<0.01$ (b).

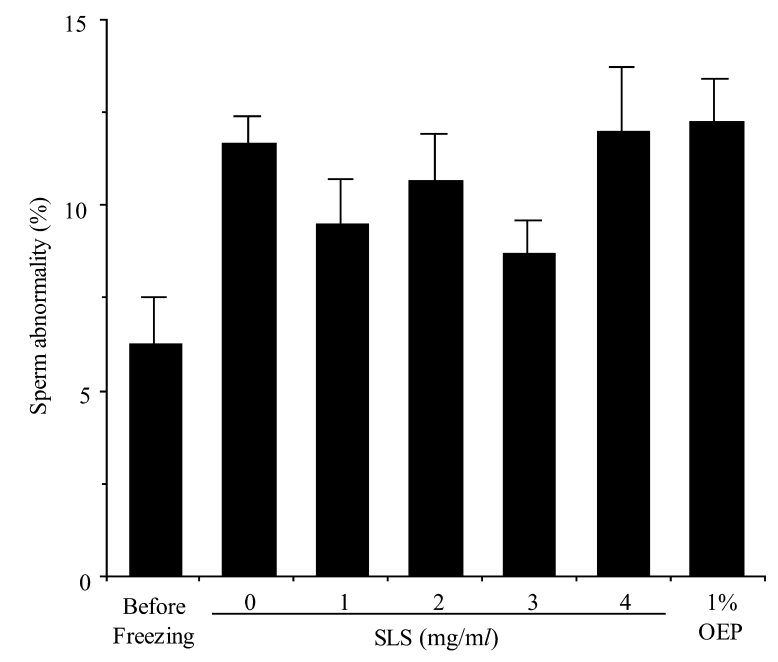

Fig. 4. Sperm abnormality before freezing and immediately after thawing for each treated group. The error bars represent the standard error of the mean $(n=6)$.

SLS was added to the second diluent is shown in Fig. 5. The acrosome cap was present in $20.6 \pm 1.2 \%$ of viable sperm in the OEP addition group and $12.2 \pm 1.7 \%$ of viable sperm in the non-OEP addition group, being significantly higher $(\mathrm{P}<0.01)$ in the former, immediately after thawing. Similarly, the acrosome cap was present in $30.8 \pm 1.4 \%$ of viable sperm in the SLS addition group and $20.8 \pm 4.6 \%$ of viable sperm in the non-SLS addition group, showing no significant difference.
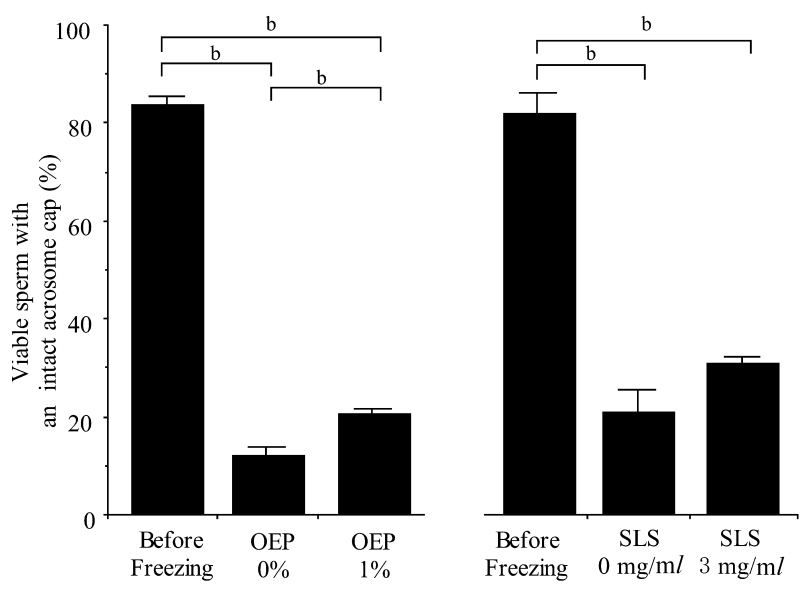

Fig. 5. The percentages of viable sperm with an intact acrosome cap before freezing and after thawing. The error bars represent the standard error of the mean $(n=5)$. Significantly different between the two groups at $\mathrm{P}<0.01$ (b).

\section{DISCUSSION}

This study showed that addition of OEP or its main constituent, SLS, along with glycerol to a cat ejaculate maintained it at a high quality after freeze-thawing, as in cryopreservation of boar [12] and dog [16, 17] semen. In this study, addition of OEP at $1 \%$ to the extender was effective for preservation of feline sperm properties during cryostorage. Addition of $3 \mathrm{mg} / \mathrm{m} l \mathrm{SLS}$ was also effective, though its level of effect was lower than that of $1 \%$ OEP.

Axnér et al. [5] reported that addition of $0.5 \%$ Equex STM paste to feline epididymal sperm resulted in lower sperm motility 4-6 hr after thawing than when no Equex 
STM paste was added. This was not the case in the present study: sperm motility did not decrease below the control level (no addition) after addition of 1\% OEP or $3 \mathrm{mg} / \mathrm{m} l$ SLS to cat ejaculates. Axnér et al. [5] examined sperm properties by maintaining sperm at $38^{\circ} \mathrm{C}$ after thawing, while we examined them at $20^{\circ} \mathrm{C}$. In their experiment, sperm seemed to suffer toxic effects of glycerol and Equex STM paste at higher temperature compared with the present study. Another possibility for this discrepancy may be the origin of the sperm (epididymal or ejaculated sperm).

In Experiment 2, the $3 \mathrm{mg} / \mathrm{ml} \mathrm{SLS}$ addition group showed favorable time-dependent changes in sperm properties after freeze-thawing compared with the other concentration groups. However, significant differences were observed only in sperm motility and viability between the 3 and $0 \mathrm{mg} /$ $\mathrm{m} l$ SLS addition groups.

The percentage of viable sperm with an intact acrosome cap was compared in each animal of the OEP and SLS groups between with and without addition of $1 \%$ OEP or 3 $\mathrm{mg} / \mathrm{m} l$ SLS. Therefore, direct statistical comparison between the OEP and SLS groups was impossible, but the percentage of sperm retaining the acrosome cap was clearly higher with than without addition of $\mathrm{OEP}(\mathrm{P}<0.01)$, and this result was in agreement with the report by Axnér et al. [5] that the acrosome cap was protected by addition of Equex STM paste. This suggests that addition of $1 \%$ OEP to sperm extender protects acrosome caps from cryoinjury. On the other hand, the protecting effect of $3 \mathrm{mg} / \mathrm{ml}$ SLS addition seems to be poor compared with $1 \%$ OEP addition.

In Experiment 1, the beneficial effect of $1 \%$ OEP addition disappeared $4 \mathrm{hr}$ after thawing, although it continued for 6 $\mathrm{hr}$ in Experiment 2. This discrepancy may be due to the sensitivity of each sperm to OEP. In Experiment 3, the difference in the percentages of viable sperm with an acrosome cap between the $0 \%$ OEP and $0 \mathrm{mg} / \mathrm{m} l \mathrm{SLS}$ groups immediately after thawing (12.2 \pm 1.7 vs. $20.8 \pm 4.6 \%$, respectively) is considered to have been caused by the difference in the sperm used.

In conclusion, addition of OEP at $1 \%$ or SLS at $3 \mathrm{mg} / \mathrm{m} l$ to the extender of frozen feline sperm was effective for preservation of sperm properties after freeze-thawing. However, our results suggested that addition of OEP is superior to addition of SLS, its primary component. Thus, it is possible that an OEP component other than SLS has favorable effects on frozen ejaculated cat semen. Further studies are necessary to compare the conception rates achieved by artificial insemination using cryopreserved semen.

\section{REFERENCES}

1. Aboagla, E. M. and Terada, T. 2004. Effects of supplementation of trehalosa extender containing egg yolk with sodium dodecyl sulfate on the freezability of goat spermatozoa. Theriogenology 62: 809-818.

2. Aboagla, E. M. and Terada, T. 2004. Effect of egg yolk during the freezing steps of cryopreservation on the viability of goat spermatozoa. Theriogenology 62: 1160-1172.

3. Ahmad, K. and Foote, R.H. 1986. Postthaw survival and fertility of frozen bull spermatozoa treated with antibiotics and detergent. J.Daily Sci. 69: 535-541.

4. Arriola, J. and Foote,R.H. 1987. Glycerolation and thawing effects on bull spermatozoa frozen in detergent-treated egg yolk and whole egg extenders. J. Dairy Sci. 70: 1664-1670.

5. Axnér, E., Hermansson, U. and Linde-Forsberg, C. 2004. The effect of Equex STM paste and sperm morphology on post-thaw survival of cat epididymal spermatozoa. Anim. Reprod. Sci. 84: 179-191.

6. Chatdarong, K., Axnér, E., Manee-In, S., Thuwanut, P. and Linde-Forsberg, C. 2007. Pregnancy in the domestic cat after vaginal or transcervical insemination with fresh and frozen semen. Theriogenology 68: 1326-1333.

7. Dewit, M., Marley, W.S., Graham, J.K. 2000. Fertilizing potential of mouse spermatoza clyopreservation in a medium containing whole eggs. Cryobiology 40: 36-45.

8. Hori, T., Kaseki, H., Fukuhara, Y., Oba, H., Mizutani, T., Kawakami, E. and Tsutsui, T. 2006. Effects of addition of sodium lauryl sulfate on frozen-thawed canine spermatozoa. $J$. Vet. Med. Sci. 68: 1125-1128.

9. Kato, S., Miyano, T., Nanjo, I. Yasui, T. and Kanda, S. 1990. Effect of concentration of sodium laurylsulfate on motility and acrosome morphology of frozen boar spermatozoa. Jpn. J. Anim. Reprod. 36: 26-30.

10. Kawakami, E., Tsutsui, T., Yamada, Y. and Yamauchi, M. 1984. Cryptorchism in the dog: occurrence of cryptorchism and semen quality in the cryptorchid dog. Jpn. J. Vet. Sci. 46: 303-308.

11. Platz, C.C., Wildt, D.E. and Seager, S.W.J. 1978. Pregnancy in the domestic cat after artificial insemination with previously frozen spermatozoa. J. Reprod. Fertil. 52: 279-282.

12. Pursel, V.G., Schulman, L.L. and Jhonson, L.A. 1978. Effect of orvus ES paste on acrosome morphology, motility and fertilizing capacity of frozen-thawed boar sperma. J. Anim. Sci. 47: 198-202.

13. Talbot, P. and Chacon, R.S. 1981. A triple-stain technique for evaluating normal acrosome reactions of human sperm. J. Exp. Zool. 215: 201-208.

14. Tanaka, A., Kuwabara, S., Takagi, Y., Nakagawa, K., Fujimoto, Y., Murai, M. and Tsutsui, T. 2000. Effect of ejaculation intervals on semen quality in cats. J. Vet. Med. Sci. 62: 1157-1161.

15. Tsutsui, T., Wada, M., Anzai, M. and Hori, T. 2003. Artificial insemination with frozen epididymal sperm in cats. J. Vet. Med. Sci. 65: 397-399.

16. Tsutsui, T., Hase, M., Hori, T., Ito, T. and Kawakami, E. 2000. Effects of orvus ES paste on canine spermatozoal longevity after freezing and thawing. J. Vet. Med. Sci. 62: 533-535.

17. Tsutsui, T., Hase, M., Hori,T ., Komoriya, K., Shimizu, N., Nagakubo, K. and Kawakami, E. 2000. Effect of addition of Orvus ES paste to frozen canine semen extender on sperm acrosomes. J. Vet. Med. Sci. 62: 537-538.

18. Tsutsui, T., Tanaka, A., Takagi, Y., Nakagawa, K., Fujimoto, Y., Murai, M., Anzai, M. and Hori, T. 2000. Unilateral intrauterine horn insemination of frozen semen in cats. J. Vet. Med. Sci. 62: 1247-1251.

19. Villaverde, A.I., Melo, C.M., Martin, I., Ferreira, T.H., Papa, F.O., Taconeli, C.A. and Lopes, M.D. 2009. Comparison of efficiency between two artificial insemination methods using frozen-thawed semen in domestic cat (Felis catus): artificial insemination in domestic cats. Anim. Reprod. Sci. 114: 434-442.

20. Yin, X.J., Lee, H.S., Yang, C.J., Bae, I., Oh, D.H., Cho, S.G. and Kong, I.K. 2007. Effect of insemination time and method on fertilization and delivery rate at the onset of estrus cats. Asian-Aust. J. Anim. Sci. 20: 677-681. 